\title{
"LO QUE UNA SUEÑA TIENE SU AQUÉL" LA EXPLORACIÓN DEL INCONSCIENTE EN FORTUNATA Y JACINTA
}

A Claudio Guillén

\section{O Inconsciente}

O espectro familiar que anda comigo, Sem que pudesse ainda verl-he o rosto, Que umas vezes encaro con desgosto E outras muitas ansioso espreito e sigo,

E um espectro mudo, grave, antigo Que parece a conversas mal disposto... Ante esse vulto, ascético e composto Mil vezes abro a boca... e nada digo.

Só uma vez ousei interrogá-lo:

"Quem es (lhe perguntei com grande abalo) Fantasma a quem odeio e a quem amo?

— "Teus irmãos (respondeu) os vãos humanos, Chaman-me Deus, há mais de dez mil anos... Mas eu por mim nao sei como me chamo...

Antero de Quental, $1886^{1}$.

1 Sonetos Completos e Poemas Escolhidos, Seleçao, revisão e prefacio de Manuel Bandeira, Livros de Portugal, Rio de Janeiro, 1942, p. 261. Galdós tenía un ejemplar (con las páginas cortadas, es decir, probablemente leído) de $O_{s}$ sonetos completos de Quental (Porto, 1886) en su biblioteca. V. H. CHONON BerKowitz, La biblioteca de Benito Pérez Galdós, El Museo Canario, Las Palmas de Gran Canaria, 1951. 


\section{INTRODUCCIÓN}

La afición de Galdós por la psiquiatría ha sido notada, entre otros, por Kercheville/Eliot (1940), Cardona (1946), Eoff (1954); Gullón (1957), Schraibman (1960), Gillespie (1966), Allen (1968), Bosch (1971), Penuel (1972), Zlotchew (1977), Engler (1977) y Gilman $(1981)^{2}$. Unos se han ocupado de la creación de personalidades anormales: Paulita Porreño en La Fontana de Oro (1867-1868), Anselmo en La sombra (1870), Maxi en Fortunata y Jacinta (1887), Abelarda Villamil en Miau (1888), el protagonista en Ángel Guerra (1890-1891), Daniel Malavella en La loca de la casa (1892), y Rafael del Águila en la serie de Torquemada (1889-1895); muy pocos, de los sueños. Los más reconocen en Galdós, por su afinidad con Charcot, Braid y Liébault ${ }^{3}$, un precursor de Freud (aunque no falta quien vea en el novelista un antifreudiano a la manera de Pavlov), así como de la psicología de masas e incluso de la psicología humanística.

¿A qué se debe esta indagación pionera en el mundo del inconsciente que le ha merecido a don Benito los epítetos de "novelista psicológico", "psicólogo literario-social"', y hasta "psiquiatra" ?5 Lo primero que hay que considerar es que Galdós es hombre de su siglo, y que el interés del diecinueve en la psicología antecede por mucho al mismo Freud. Ya desde 1846 Carus

${ }^{2}$ F. M. Kercheville y L. W. Eliot, "Galdós and Abnormal Psychology", H. 23 (1940), 27-36; Rodolfo Cardona, Introducción a La sombra, W. W. Norton, New York, 1946, pp. ix-xxvi: Sherman Eoff, The Novels of Pérez Galdós: The Concept of Life as a Dynamic Process, St. Louis, 1954; RICARDo Gu. LLón, Est. prelim. y bibliografía a Miau, Editorial Universitaria, Puerto Rico, 1957, pp. 155-230; Joseph Schraibman, Dreams in the Novels of Galdós, Hispanic Institute in the United States, New York, 1960; Gerald Gillespie, "Dreams and Galdós", $A G, 1$ (1966), 107-115; Rupert C. AlleEN, "Pobreza y neurosis en Misericordia de Galdós", $H f$, 1968, núm. 33, 37-38; RafaEL Bosch, "La sombra y la psicopatología de Galdós", $A G, 6$ (1971), 21-42; ARNOld Penuel, "Galdós, Freud and Humanistic Psychology", H, 55 (1972), 66-75; Clark M. Zlotchew, "Galdós and Mass Psychology", $A G, 12$ (1977), 5-19; KaY ENGler, "The Ghostly Lover: The Portrayal of the Animus in Tristana", $A G, 12$ (1977), 95-109; StePhen Gilman, Galdós and the Art of the European Novel: 1867-1887, Princeton University Press, Princeton, NJ, 1981.

3 Alejándose de la psicología experimental alemana, J. M. Charcot (1825-1895), A.A. Liébault (1823-1893) y James Braid (ca. 1795-1860) atribuyeron algunos desórdenes nerviosos, como la histeria, a la sugestión y los trataron exitosamente mediante la hipnosis (PENUEL, art. cit., p. 66).

${ }^{4}$ EOFF, op. cit.

5 Joan Connely Ullman y George Allison, "Galdós as Psychiatrist in Fortunata y Jacinta", $A G, 9$ (1974), 7-36. 
sostiene en su Psyche que el inconsciente es la llave para entender el consciente 6 , y en su voluminosa Filosofía del inconsciente, de 1868, Eduard von Hartman traza el estudio de éste hasta el siglo dieciocho: Leibniz, Kant, Fichte, Schelling, $\mathrm{Hegel}^{7}$.

Aun cuando en España el discurso científico se vio adversamente afectado por la Restauración, el período republicano resultó propicio para el debate de nuevas ideas ${ }^{8}$. Sin embargo, como advierten Ullman y Allison, en la controversia sobre la génesis de la psicopatología, España se quedó rezagada en un determinismo fisiológico que ve la enfermedad mental como producto de tara, accidente o dolencia física. Las nociones psiquiátricas modernas que postulan el origen psicológico de los disturbios mentales no cuajan en Europa sino hasta los años de 1890, llegando tardíamente a España en la segunda década de nuestro siglo.

Los más de los estudios de psiquiatría o temas aledaños consignados en el catálogo que hace Berkowitz de la biblioteca de Galdós ${ }^{9}$ son posteriores a Fortunata y Jacinta (1887), la novela que nos ocupa: A. I. Hardy y J. M. Charcot, Informe sobre el estado mental de Martin Larios y Larios (1889), Paul Bourget, Essais de psychologie contemporaine (1893), Nouveaux essais de psychologie contemporaine (1894), R. Mella, Del amor (modo de acción y finalidad social), Victor Melcior y Farre, La enfermedad de los místicos (patología psiquica) (1900), Los estados subconscientes y las aberraciones de la personalidad (1904), Prudencio Fernández Solares, Naturaleza y cultivo de la memoria (1904), Melcior y Farre, ¿Puede considerarse la voluntad como una fuerza medicatriz? (1908). Anteriores, sólo los Estudios clínicos de neuropatología, de José Armangue y Tuset (1884), y La soledad, de Juan Jorge Zimmermann (1873). Sin fecha está La expresión de las emociones, de Carlos Darwin. Naturalmente, el contenido de una biblioteca no agota el caudal de lecturas de su dueño. Así, por ejemplo, Galdós menciona en Fortunata y Jacinta a Pedro Mata y Fontaner, autor de un título que no consta en su biblioteca, el Tratado de la razón humana en sus estados intermedios, sueños, pesadillas, sonambulismo... (1864); Mata y Fontaner ofreció una serie de con-

${ }^{6}$ GiLlespie, op. cit., p. 111.

${ }^{7}$ Philosophy of the Unconscious, tr. William Chatterton, MacMillan, New York, 1884, 3 ts. Debo este dato, así como la noticia del soneto de Quental sobre el inconsciente que sirve de epígrafe a este trabajo, a Claudio Guillén.

8 Thomas F. Glick, "The Naked Science: Psychoanalysis in Spain, 1914-1948', Comparative Studies in Society and History, Cambridge, 24 (1982), 533-536.

${ }^{9}$ Berkowitz, op. cit. Sólo damos los títulos de los libros cuyas páginas había cortado Galdós. 
ferencias en el Ateneo de Madrid, donde se encontraban sus libros ${ }^{10}$.

Podemos inferir, entonces, que el conocimiento psiquiátrico que Galdós revela en Fortunata y Jacinta no es, en lo esencial, producto de lecturas médicas. Él mismo confiesa, en el prólogo al libro de su amigo, el doctor Manuel Tolosa Latour (Niñerías, de 1889), su "flirteo" con la medicina, incapaz de un "noviazgo" serio por el esfuerzo disciplinado que éste requeriría ("demasiados perendengues" )". La clave está, entonces, en la observación amorosa de la realidad.

Y en esta observación empírica, Galdós comparte su fascinación por el crimen con los grandes novelistas del diecinueve, como Balzac (Une ténébreuse affaire, 1841-1842), Dostoievski (Crimen y castigo, 1866; El idiota, 1868-1869; Los endemoniados, 1871), y Dickens, que apenas tiene novela sin criminal. Son notables en este sentido dos instancias en que sigue de cerca un crimen y escribe sobre éste varias crónicas para La Prensa de Buenos Aires; el del cura Galeote (18 de abril de 1886) suscita tres informes publicados entre el 22 de mayo y el 20 de noviembre de ese año, y el de la calle de Fuencarral (1 de julio de 1888); produce también otras tres crónicas, que La Prensa da a la luz entre el 19 de julio y el 15 de agosto de 1888. En este último caso, Galdós literaturiza su experiencia en dos novelas, La incógnita y Realidad (1888-1889), aunque más que la personalidad criminal le interesa, como señala Berkowitz, la abismal diferencia entre la verdad, que sólo reside en el interior de la conciencia humana, y la versión pública y contradictoria de ésta (que se encuentra en las declaraciones de los testigos y en las opiniones vertidas por la prensa del día $)^{12}$.

No hay que descartar tampoco el peso de las lecturas literarias de Galdós en su atención al comportamiento desviado y al mundo de los sueños. Ya en 1924 Salvador de Madariaga, en sus

10 El dato ha sido señalado por SChraibman, op. cit.

11 Citado por Ullman y Allison, op. cit.

12 Opino que más que la distancia entre la verdad absoluta y la verdad relativa, ambas novelas exploran la distancia entre realidad y ficción; un poco lo que hace García Márquez en Crónica de una muerte anunciada, reflexión sobre la conciencia de la ficcionalidad de la literatura. Palabras y cosas no se corresponden, y aquéllas no pueden "recomponer el espejo roto de la memoria", al decir del colombiano. Sobre el crimen de la calle de Fuencarral, y la trayectoria suceso $>$ informe periodístico $>$ versión literaria, tiene DENAH LIDA dos importantes trabajos: "El crimen de la calle de Fuencarral"', HJC, pp. 275-283; y "Galdós, entre crónica y novela", $A G, 8$ (1973), 63-77. 
Semblanzas literarias de los contemporáneos, halló antecedentes dostoievskianos en Maxi Rubín. Y aunque las novelas del ruso no constan en la biblioteca de Galdós. Ortiz Armengol nos recuerda cómo doña Emilia Pardo Bazán (colega, amiga y compañera de andanzas eróticas de don Benito) pronunció tres conferencias a la que asistió nuestro autor en el Ateneo de Madrid sobre La revolución y la novela en Rusia en 1887 (el libro, publicado ese mismo año, sí figura en la biblioteca de Galdós). Es muy probable que la Pardo Bazán compartiera con él su deslumbramiento por Crimen y castigo, de $1866^{13}$. Por otra parte hay que contar con el hecho de que, al dominar tanto el inglés como el francés, Galdós no dependía exclusivamente de traducciones al castellano, naturalmente tardías.

Gilman ve en Fortunata y Jacinta una "ofensiva cervantina" a la herencia de Zola; pero ciertamente para poder subvertir el naturalismo hubo de digerirlo y asumirlo en sus primeras novelas ${ }^{14}$. El interés de la novela naturalista por la ciencia y la medicina parecería explicar en parte la atención de ésta a la dimensión psicológica del hombre; sin embargo, es curioso constatar cuánto más "científica"' y psicologista resulta hoy la novela realista que su precedente. En unas atinadas observaciones sobre La Regenta, de Clarín (también "precursora' del psicoanálisis), nota Rutherford:

The realist novelist differs from his naturalistic counterpart in that he does not try to confirm theories but to explore experience. For the naturalist, the novel is an illustration of the validity of the scientific approach to knowledge. Despite what naturalists such as Zola claimed, the realistic novel is both more objective than the naturalistic novel and more likely to stand the test of time; this is precisely because it is less influenced by the scientific ideas of its own period, which must, sooner or later, be superseded by others. So the novels of the naturalists are interesting in proportion as they wriggle free from the clutches of their own theory. So, also, the realistic novelist can make discoveries which psychologists only make many years later ${ }^{15}$.

13 Pedro Ortiz Armengol, Introd. y notas a la ed. de Fortunata y Jacinta conmemorativa del CL aniversario de la fundación de la Casa Editorial Hernando (1828-1878), Hernando, Madrid, 1979, t. 1, pp. 48-49.

GaLdós reseñó estas charlas: "Conferencias de Emilia Pardo Bazán en el Ateneo" [Madrid, 15 de abril de 1887], en Obras inéditas, t. 2: Arte y crítica, ed. Alberto Ghiraldo, Renacimiento, Madrid, 1923, pp. 203-208.

${ }^{14}$ Gilman, op. cit.

${ }^{15}$ JOHN RUTHERFord, Introd. a la primera traducción inglesa de $\mathrm{La} R \boldsymbol{e}^{-}$ genta, de LeOPOLDO Alas, Penguin Books, Middlesex-New York, 1984, pp. 9-10. 
Ya Dostoievski había notado la relación entre realismo literario, observación empírica y psicología:

They call me a psychologist. This is not true. I am merely a realist in the higher sense of the word, that is, I depict all the depths of the human soul ${ }^{16}$.

En un trabajo reciente ${ }^{17}$ hice una lectura jungiana de Fortunata y Jacinta, tomando como punto de partida los sueños de los personajes femeninos, y finalmente, considerando la novela como un sueño de su autor desde la perspectiva de los arquetipos. Hoy, al tener la oportunidad de examinar el manuscrito original del texto ${ }^{18}$, que tiene dos versiones, una preliminar (ALPHA) y otra definitiva (BETA) ${ }^{19}$, quiero auscultar la dinámica del proceso de indagación del inconsciente en Fortunata y Jacinta, que va de la primera a la segunda versión de la obra, y en algún caso, de ésta al texto publicado. El presente ensayo, pues, complementa el anterior, al ver, como diría Cervantes, "el tapiz por el revés".

Ese mundo que está debajo escondido y que para Fortunata gobierna al que se ve, al que Maxi llama, solemne, "la inspiración poética" o "'la poesía, estado morboso" (p. 582) ${ }^{20}$, y el narrador, implacablemente burlón, "el inconmensurable hueco de la mente humana' (p. 296), está aún poco explorado en la versión ALPHA del manuscrito, probablemente por la naturaleza esquemática de la misma: se trata de un borrador sólo bien elaborado en su primera parte, que se corresponde a veces casi exactamente con la misma en BETA, y balbuciente o telegráfico a partir de la

${ }^{16}$ Citado por Ernest J. Simmons, Introd. a Crime and Punishment, Vintage Books, New York, 1950. Para una descripción pre-freudiana de los mecanismos y funciones del sueño, véase The Idiot, tr. Constance Garnett, William Heinemann, Melbourne-London-Toronto, 1958, pp. 443-444.

17 "Sueños de mujeres: la voz del anima en Fortunata y Jacinta de Galdós", $H R$ (en prensa).

18 Pasé el verano de 1985 trabajando con el manuscrito en la Houghton Library, de Harvard, donde aparece catalogado como Ms SPAN 93. Debo a Stephen Gilman su generosa acogida y conversaciones deliciosas sobre Fortunata en Cambridge.

${ }^{19}$ Pongo definitiva entre comillas, pues, como se verá, Galdós corregía minuciosamente las galeradas, lo que convierte al texto publicado en la versión realmente final. Diane BeTH HyMAN, autora de una transcripción inédita de la versión preliminar, nombra a ésta ALPHA y a la segunda, BETA (The Fortunata y Jacinta Manuscript of Benito Pérez Galdós, tesis doctoral, Harvard, 1972).

${ }^{20} \mathrm{~A}$ partir de aquí cito por la edición de Porrúa de Fortunata y Jacinta. (Dos historias de casadas), México, 1975. 
segunda ${ }^{21}$. Lo mismo sucede en ALPHA con el material histórico, documental: está apenas insinuado.

Pero en esta primera versión, que más que nada traza la trama y presenta los personajes, éstos sueñan, y como puntualiza Mauricia en la segunda, "lo que una sueña tiene su aquél" (p. 285). En total, hay 8 sueños en ALPHA: 2 (de Jacinta) se reproducen con leves alteraciones en BETA, y 6 (5 de Fortunata, que es consistentemente la "soñante mayor", y uno insólito, por ser el único en la novela soñado por Juanito) desaparecen en la segunda versión.

Me propongo, entonces, 1) presentar cada uno de los 6 sueños que pertenecen exclusivamente a ALPHA, comentándolos a la luz de su posterior desaparición en BETA; 2) mostrar cómo y por qué cambia un mismo sueño de ALPHA a BETA y 3) de BETA al texto publicado; finalmente, 4) ocuparme del caso de Maxi, cuya transformación de ALPHA a BETA es sorprendente, y bien puede haber tenido que ver con el suceso del crimen de Galeote, como sugirieron en su momento Ullman y Allison.

\section{LOS SUEÑOS INÉDITOS DE ALPHA}

Comienzo por Fortunata, presentando los 5 sueños en el orden de su aparición:

(1) Fortunata se adormecía con visiones de hombres guapos, bien vestidos y que montaban a caballo con donaire. Después vio la botica horrible hacerse absurda, y su marido como un mico vestido... Los señoritos guapos pasaban por la calle, y su marido estaba dentro machacando con su almirez. Despertó sobresaltada (A 539, H 322) ${ }^{22}$.

(2) Se volvió a adormecer. Su marido la tenía entre sus brazos [...] De repente Fortunata dio un grito y se incorporó... ¿Quién está ahí, quién es?... Había dejado la luz encendida, era una vela que agonizaba, y tan pronto echaba una luz vivísima, como dejaba la habitación en tinieblas... Un hombre... Fortunata se levantó... No había nada. Era una alucinación... (A 540, H 323).

(3) [faltan páginas iniciales] besos y le dijo: vas a tener un hijo mío... otro Juanín. Luego le dijo: dame tu vida para que yo no padezca, y ella se sacaba el corazón y se lo daba. Despertó.

${ }^{21}$ Para un examen de las variantes entre una y otra versión, tanto los cambios en los personajes principales como en los finales, véase mi trabajo "Fortunata y Jacinta en gestación: de la versión ALPHA a la versión BETA del manuscrito galdosiano", $A G$ (en prensa). 
Al día siguiente se encontró con la cabeza llena de aquellas cosas (A 573, H 341).

(4) El sueño rindió a Fortunata. Severiana dormía también. Fort. tuvo un ligero desvanecimiento, en el cual vio a Jacinta delante de sí. La cogía por el brazo... La sacudía. La otra temblaba y pedía perdón. Después parecíale que Jacinta estaba mala. Fortunata estaba en la cabecera de su cama, había traído de la botica un vasito de veneno, y lo había echado en la sopa en que bebía la enferma. Ella bebió y se quedaba muerta... Fortunata se llegaba a ella la besaba y le decía: Vete al cielo que es tu puesto y déjame a mí la tierra. Despertaba cubierta de sudor frío... (A 767, H 440-441).

(5) Amaneció. Fort. se durmió un poco en la silla y volvió a soñar horrores. Ella y Jacinta se pegaban... Jacinta vencida lloraba y decía: por qué me matas. Luego se abrazaban y se besaban, jurándose ser amigas (A 769-770, H 442).

Tres de los sueños $(1,4,5)$ muestran a Fortunata bajo un prisma claramente negativo: el primero revela su frivolidad deslumbrada ante la guapura, buen vestir y mejor montar de los señoritos en su ocio habitual, y su crueldad ante Maxi, quien, trabajando honradamente, sólo le inspira burlas. El cuarto es el más elaborado y vívido, y presenta a una Fortunata perversa que asesina fríamente a Jacinta y luego la manda, sardónicamente, y tras un beso de Judas, a irse al cielo para ocupar ella su puesto en la tierra. El quinto parece en parte una continuación de aquél, ya que dice el narrador que Fortunata "volvió a soñar horrores": es otro sueño de violencia, en que ambas mujeres se pegan y vence la soñante. No es difícil inferir el porqué de la eliminación de estos sueños, si tenemos en cuenta cómo Galdós “ "angeliza" a su protagonista de ALPHA a BETA, y aun de BETA al texto publicado, lo que estudio en otro lugar ${ }^{23}$. Los sueños 2 y 3 posiblemente parecieron a Galdós un tanto exagerados, el segundo por truculento, el tercero por melodramático. Sin embargo en éste y en el quinto se anticipa el final de la novela (el nacimiento de Juanín y la fusión espiritual de las dos mujeres), final que a nivel consciente aún no está claro para Galdós en el momento en que esto escribe ${ }^{24}$.

22 Desde aquí, cada vez que cite un texto de la primera versión del manuscrito, daré la paginación de ALPHA (A _ ) y la correspondiente de la transcripción de Hyman ( $\mathrm{H}_{-}$). BETA será (B _ $)$. Agradezco a Houghton Library me permita citar del manuscrito.

23 Véase nota 21.

${ }^{24}$ Me refiero a mi exposición sobre los posibles finales en ALPHA en "Fortunata y Jacinta en gestación: de la versión ALPHA a la versión BETA del manuscrito galdosiano". 
El único sueño de Juanito está, lamentablemente, incompleto, ya que faltan las páginas iniciales en ALPHA. Dice así:

San Pedro. Veíamos al Padre Santo diciendo misas con una manta verde... luego apareció Pepito y echándose a tus pies te hacía una declaración de amor. Yo lo oía tan tranquilo. Eso es lo más particular. Tú te levantaste y él lanzó una exclamación de desconsuelo al mirarte en pie. Dios mío - exclamó-, está embarazada.

Jacinta no podía contener la risa. - Embarazada! Eso querías tú... pues oye. Pepito salió dando pasos largos como los de los cómicos. Y yo te miré. Tenías una barriga del tamaño de esta cama. Pero no te rías, no alborotes. El Padre Santo pasaba entonces una procesión muy vistosa. Pepito iba delante con un incensario... Y vida mía. Entonces desperté (A 331, H 220).

Juanito tiene este sueño cuando Jacinta se dispone - sin él saberlo- a hacer las averiguaciones para conseguir el falso Juanín, de manera que se trata de un sueño premonitorio hasta cierto punto. Pepito es un personaje ridículo, obsesionado por la idea de la preñez de su novia, que se descarta en BETA. No estoy segura si Galdós eliminó el sueño por ser demasiado grotesco (lo que va con el Juanito de ALPHA, personaje caricaturesco y cómico, y por tal, más simpático que el de BETA, que se toma en serio: parece que el novelista quiso abortar cualquier posibilidad de gracia en el personaje) o porque por más estrambótico que resultara, siempre suponía concederle más vida interior a un ser que quería presentar como hueco (falso, frío, "de yeso") en BETA.

\section{DE ALPHA A BETA}

El primer sueño de Jacinta en ALPHA se reproduce en BETA con mínimas alteraciones:

Con lo que no se conformaba era con no tener chiquillos. [...] Tanto pensaba en esto que su imaginación se extraviaba. Por las noches, medio dormida, tenía alucinaciones. Sentía por sus pechos un contacto caliente, y una boca que lo chupaba. Daba un grito ¡ah! despertándose. Su marido le hablaba desde la otra cama: Jacintilla ¿qué tienes, vida? Pesadilla?... Nada, hijo, un sueño. Y no quería contar aquellas cosas porque todos en la casa se reían de ella (A 286-287, H 191-192).

Con lo que no se conformaba era con no tener chiquillos [...] De tanto cavilar en esto, su mente padecía alucinaciones y desvaríos. Algunas noches, en el primer período del sueño, sentía sobre su se- 
no un contacto caliente y una boca que la chupaba. Los lengüetazos la despertaban sobresaltada, y con la tristísima impresión de que todo aquello era mentira, lanzaba un jay!, y su marido le decía desde la otra cama:

— ¿Qué es eso nenita?... ¿Pesadilla?

-Sí, hijo, un sueño muy malo.

Pero no quería decir la verdad por temor de que Juan lo tomara a risa (p. 90).

El "elemento añadido" en la segunda versión son los "lengüetazos" del chiquillo, que anticipa las variantes que introduce la refundición de BETA del segundo sueño, que lee así en ALPHA:

Una noche fue al teatro Real de mala gana. Tenía sueño, porque la noche anterior la había pasado junto a su hermana Candelaria, que tenía un niño malo. Desde que empezó la ópera sentía tal sueño, que se puso en la última silla de atrás, y con disimulo cerró los ojos. Fue un sueño breve y profundo, uno de esos sueños en que se ven las cosas con pasmosa claridad. Se vio con un nene delante que se le subía por las piernas y le metía las manos en el pecho... Quita, caca, le decía ella. ¡Qué asco!... Y él insistiendo, pesado, llorón. "Quita, ay qué fea cosa... Está negra, está amarga. Entonces él se metió la cabeza por entre la ropa. Tenía una fuerza hercúlea; ella no podía hacer nada contra él. Es para el gato... cosa fea... quita, quita". Ella le cogió las dos manos y él lanzó un grito tan estrepitoso que asustada Jacinta abrió los ojos. El grito era el del coro y la orquesta ambos. La escena estaba llena de gente y un hombre, una especie de maricón con melenas y caderas, un tenor feísimo daba unos chillidos con la cara descompuesta.[...]

Después se ocupó Jacinta de mirar al palco donde iba su marido. No parecía (A 287-288, H 192-193).

En BETA el sueño se amplía considerablemente:

Hallábase Jacinta en un sitio que era su casa y no era su casa... Todo estaba forrado de un satén blanco con flores que el día anterior habían visto ella y Barbarita en casa de Sobrino... Estaba sentada en un puff y por las rodillas se le subía un muchacho lindísimo, que primero le cogía la cara, después le metía la mano en el pecho. "Quita, quita..., eso es caca... ¡qué asco!..., cosa fea, es para el gato..." Pero el muchacho no se daba a partido. No tenía más que la camisa de finísima holanda, y sus carnes finas resbalaban sobre la bata de seda de su mamá. Era una bata de color azul gendarme, que varias semanas antes había regalado a su hermana Candelaria. "No, no, eso no..., quita..., caca..." Y él, insistiendo siempre, pesadito, monísimo. Quería desabotonar la bata y meter 
mano. Después dio cabezadas contra el seno. Viendo que nada conseguía, se puso serio, tan extraordinariamente serio, que parecía un hombre. La miraba con sus ojazos vivos y húmedos, expresando con ellos y en la boca todo el desconsuelo que en la humanidad cabe. Adán, echado del Paraíso, no miraría de otro modo el bien que perdió. Jacinta quería reírse, pero no podía, porque el pequeño le clavaba su inflamado mirar en el alma. Pasaba mucho tiempo así y el niño-hombre mirando a su madre, y derritiendo lentamente la entereza de ella con el rayo de sus ojos. Jacinta sentía que se le desgajaba algo en sus entrañas. Sin saber lo que hacía, soltó un botón... Luego otro. Pero la cara del chico no perdía su seriedad. La madre se alarmaba y... fuera el tercer botón... Nada, la cara y la mirada del nene siempre adusta, con una gravedad hermosa, que iba siendo terrible... El cuarto botón, el quinto, todos los botones salieron de los ojales, haciendo gemir la tela. Perdió cuenta de los botones que soltaba. Fueron ciento, puede que mil... Ni por ésas... La cara iba tomando una inmovilidad sospechosa. Jacinta, al fin, metió la mano en su seno, sacó lo que el muchacho deseaba, le atrajo a sí, y, quieras que no, le metió en la boca... Pero la boca era insensible, y los labios no se movían. Toda la cara parecía de una estatua. El contacto que Jacinta sintió en parte tan delicada de su epidermis era el roce espeluznante del yeso, roce de superficie áspera y polvorosa. El estremecimiento que aquel contacto le produjo dejóla por un rato atónita; después abrió los ojos... (pp. 91-92).

El sentido de ambos sueños en ALPHA, de pura frustración maternal, cambia redicalmente en BETA, con los siguientes detalles eróticos:

primer sueño

lengüetazos

segundo sueño

Estaba sentada en un puff...

No tenía más que la camisa de finísima holanda, y sus carnes finas resbalaban sobre la bata de seda de su mamá.

Quería desabotonar la bata y meter mano.

...Se puso serio, tan extraordinariamente serio, que parecía un hombre.

La miraba con sus ojazos y vivos y húmedos, expresando en ellos y en la boca todo el desconsuelo que en la humanidad cabe. Adán, echado del Paraíso, no miraría de otro modo el bien que perdía. 
...el pequeño le clavaba su inflamado mirar en el alma.

Pasaba mucho tiempo así y el niño-hombre mirando a su madre, y derritiendo lentamente la entereza de ella con el rayo de sus ojos.

Jacinta sentía que se le desgajaba algo en sus entrañas.

Sin saber lo que hacía, soltó un botón... Luego otro [...] El cuarto botón, el quinto, todos los botones salieron de los ojales, haciendo gemir la tela.

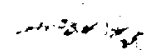

Obviamente estamos ante un sueño de frustración erótica, en que el deseo por Juanito, el "niño-hombre", no se ve realizado ${ }^{25}$. Ello da una dimensión más humana a la Jacinta de BETA, paradógicamente menos sensual que la de ALPHA.

\section{DE BETA AL TEXTO PUBLICADO}

Tomo como ejemplo el sueño premonitorio de Fortunata, cuyo simbolismo fálico de tubos, lápices, grifos y llaves en un ambiente de humedad anuncia la llegada de Juanito Santa Cruz. Lee así en el texto publicado:

En tal situación siente vivos impulsos de salir a la calle [...] Sale, se dirige a la calle de la Magdalena, y se para ante el escaparate de la tienda de tubos obedeciendo a esa rutina del instinto por la cual, cuando tenemos un encuentro feliz en determinado sitio, volvemos al propio sitio creyendo que le tendremos una segunda vez. ¡Cuánto tubo! Llaves de bronce, grifos y multitud de cosas para llevar y traer el agua [...] Y el pianito sigue tocando aires populares, que parecen encender con sus acentos de pelea la sangre de toda aquella chusma [...] Un individuo que sobre una mesilla de tijera exhibe el gran invento para cortar cristal, tiene que salir a espetaperros; otro que vende los lápices más fuertes del mundo (como que da con ellos tremendos picotazos en la madera sin que se les rompa la punta) también recoge los bártulos [...] El piso está humedo y los pies se resbalan. De repente, jay!, cree que le clavan un dardo. Bajando por la calle Imperial [...] viene Juanito Santa Cruz... (pp. 483-485).

Este insólito sueño permite una lectura minuciosamente freu-

${ }^{25}$ Harriet Turner da esta interpretración al sueño largo de BetA: " $\mathrm{Fa}$ mily Ties and Tyrannies: A Reassessment of Jacinta' , $H R$, 51 (1983), 20-21, que coincide con la de la autora de estas líneas en "Sueños de mujeres: la voz del anima en Fortunata y Jacinta de Galdós". 
dina. Reconocemos en primer lugar el incitador del sueño $0^{26}$, una impresión trivial de los días anteriores que no es el verdadero motivo de éste, pero que da pie para su elaboración. Fortunata le cuenta a Guillermina que el día antes pasaba por la calle de la Magdalena y se paró a ver un escaparate lleno de tubos (p. 479). Freud entiende que los sueños se dividen en tres categorías: los sueños inteligibles, que cumplen directamente deseos conscientes (casi siempre son sueños infantiles); los sueños que, aunque claros, producen un efecto de ansiedad o angustia (expresan el cumplimiento directo de deseos reprimidos); y los sueños ininteligibles, que parecen carecer de sentido (éstos expresan el cumplimiento encubierto de deseos reprimidos). El sueño de Fortunata pertenece a esta tercera categoría: abigarrado y confuso, expresa un deseo que apenas quiere confesarse a sí misma, pues está casada con Maxi y aspira a la honradez. No le causa ansiedad el sueño pues el cumplimiento del deseo reprimido está disfrazado.

Para Freud todo sueño entraña una elaboración de las ideas que contiene (dream work), lo que supone cuatro operaciones: la condensación, el desplazamiento, la representabilidad y la fachada. La condensación convierte al sueño en un texto apretado, preñado de sentidos múliples y contradictorios que se comunican con un mínimo de recursos. Son típicas de ésta las figuras compuestas de elementos que no suelen asociarse en la vigilia. En el sueño de Fortunata tenemos el "enano, un monstruo vestido con balandrán rojo y turbante, alimaña de transición que se ha quedado a la mitad del camino darwinista por donde los orangutanes vinieron a ser hombres"', hombre/animal que representa la fuerza de los instintos de la Pitusa ${ }^{27}$.

${ }^{26}$ Fundamento este análisis en las ideas de Sigmund Freud según aparecen en On Dreams [1901], tr. James Strachey, W.W. Norton, New York, 1952.

27 En el año en que Fortunata confunde a Guillermina con Mauricia la Dura (p. 472), tenemos un magnífico ejemplo de condensación. Para Freud, estas figuras compuestas "are emphasizing in an effectively abbreviated form some common characteristic of the objects which they are just combining' (p. 47). Resulta chocante pensar que Mauricia y Guillermina tengan algo en común (y no lo digo por menosprecio de la Dura, que en el fondo es mucho más caritativa que la santa, en tanto entiende la naturaleza humana). Cierto que su fusión en la mente de Fortunata representa el conflicto entre sexualidad y honradez, resuelto al final en una síntesis armónica. Pero volviendo a los personajes, ¿qué puede vincular a Mauricia, caracterizada como "loca", "tocada" y "lunática" por los que la rodean, con Guillermina? Pues precisamente la locura. Oigamos a Moreno, cuando su tía le propone la idea de fundar un manicomio: - Un manicomio! - dijo Moreno, sonriendo de un modo que le heló la sangre a su generosa tía. - Sí, no me parece mal. Y lo estrenaríamos tú y yo... (pp. 540-541). 
El desplazamiento es la operación encubridora por excelencia: lo que en el sueño resulta más vivo y ocupa el papel protagónico, no es lo más importante, sino aquello que apenas asoma. Así, en el texto de Fortunata, los tubos, llaves, grifos y lápices constituyen el eje, siendo cosas triviales, mientras que el verdadero tema del sueño aparece al final: "Bajando por la calle Imperial [...] viene Juanito Santa Cruz'.

La representabilidad es el código icónico, el lenguaje predominantemente visual del sueño. El sueño de Fortunata presenta una escena callejera muy vívida, con peleas, música de organillo, gentío. Este código tiene sus propias reglas para expresar las nociones del lenguaje articulado: por ejemplo, la conexión lógica se indica por la aproximación en el tiempo y el espacio; la relación causal, por la secuencia de dos partes del sueño (ambos procedimientos aplicables a nuestro sueño: tubos $>$ Juan), etcétera.

Finalmente, la fachada o primera interpretación (válida o no) que le da el soñante para dotarlo de coherencia. Algo de esto inferimos en el monólogo de Fortunata que sigue al sueño:

Lo que había soñado se le quedó a la señora de Rubín tan impreso en la mente como si hubiera sido realidad. Le había visto, le había hablado. Completó su pensamiento amenazando con el puño a un ser invisible: "Tiene que volver... ¿Pues tú que te creías? Y si él no me busca, le buscaré yo... Yo tengo mi idea, y no hay quien me la quite"' (p. 485).

Y como si todo esto fuera poco, hay la motivación esencial que Freud señala para los sueños (la sexual) y los símbolos eróticos universales (en este caso, fálicos).

Ahora bien, me interesa precisar los cambios del sueño entre ALPHA y la versión publicada. A primera vista ambas versiones del texto son idénticas, hasta que notamos un cambio en el tiempo verbal. El sueño en BETA, que empieza, como el de la primera edición, en presente ("En tal situación siente vivos impulsos de salir a la calle", B 600) ${ }^{28}$, pronto asume el pretérito (tanto perfecto como imperfecto, más el segundo que el primero):

Un individuo que sobre una mesilla de tijera exhibia el gran invento para cortar cristal, tuvo que salir a espetaperros y otro que vendía los lápices más fuertes del mundo (como que daba con ellos tremendos picotazos en la madera sin que se les rompiera la punta), también recogió los bártulos [...] Fortunata miraba todo esto y

${ }^{28}$ En esta sección los subrayados son míos. 
se reía. El piso estaba húmedo, y los pies se resbalaban. De repente, ¡ay! creyó que le clavaban un dardo. Bajando por la calle Imperial, en dirección al gran pelmazo de gente que se había formado, venía Juanito Santa Cruz (B 660-666).

La versión publicada transforma el pretérito en presente:

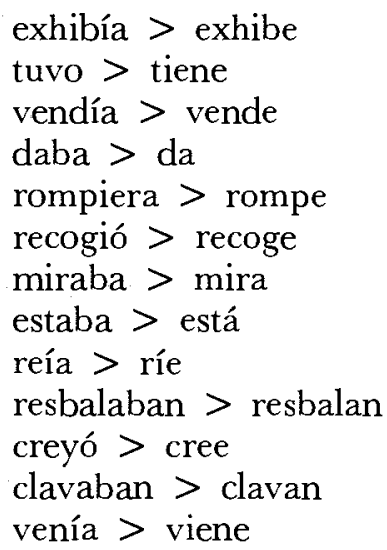

$¿$ ¿ué importancia puede tener un cambio así, aparentemente trivial? Al leer el sueño en la versión publicada, sabemos, sin poder explicar por qué, que se trata de un gran acierto. De nuevo, tenemos aquí la premonición de una importante idea de Freud: la expresión del deseo, que en el lenguaje verbal asume la forma optativa "si yo pudiera", "quisiera", etc., en el sueño tiene que rendirse a las condiciones de representabilidad, que lo muestran cumpliéndose en imágenes ahora y de verdad, en tiempo presente.

\section{El CASO DE MaXI}

Ullman y Alison concluyen su ensayo de 1974 con las siguientes palabras: "If the manuscript of Fortunata y Jacinta is extant, it would be valuable to explore how if at all, Galdós changed his characterization of Maximiliano in response to the Galeote case"'. Recordemos brevemente el famoso crimen del Domingo de Ramos de 1886. El cura Galeote, molesto por la campaña del arzobispo Martínez Izquierdo para frenar la relajación general del clero madrileño, evitando los abusos de los "curas sueltos", lo mata a tiros en la calle, en la celebración popular de la fiesta de las palmas. Galdós se interesa por el caso, que reconoce como psicopatológico en lugar de político, hasta tal punto que hace un paréntesis en la redacción de Fortunata y Jacinta (dejó el volumen II, en que 
presenta al personaje de Maxi Rubín) para preparar tres artículos sobre el crimen para La Prensa de Buenos Aires, visitó al cura en prisión, se entrevistó con su amante, y asisitió al juicio ${ }^{29}$.

No esperemos encontrar en Fortunata y Jacinta las huellas explícitas de las reflexiones periodísticas de Galdós sobre el crimen de Galeote, como es el caso de La incógnita y Realidad con relación a las crónicas en torno al crimen de la calle de Fuencarral. Sí hay un detalle menor, ciertamente irónico, y que ha observado sagazmente Matilde L. Boo ${ }^{30}$; los rasgos de Galeote, según la descripción de Galdós en La Prensa (" nariz pequeña y corva, la boca muy grande y muy separada de la nariz, los ojos negros y vivos, la frente despejada") son el modelo para los del antipático hermano de Maxi, el cura Nicolás Rubín: “La cara era desagradable, la boca grande y muy separada de la nariz, corva y chica, la frente espaciosa, pero sin nobleza'. Esto, en un nivel literal. Pero volviendo a la preocupación de Ullman y Allison, sucede algo notable con la caracterización de Maximiliano de ALPHA a BETA, que no puedo probar más allá de toda duda razonable que sea resultado de la conmoción que le causara el conocer a Galeote, pero que tampoco se explica por el mayor desarrollo que hay de los protagonistas (e incluso personajes menores) en BETA.

Porque resulta que en ALPHA Maxi no es loco. Sus condiciones aberrantes son los celos:

¿Cómo descubre todo Maxi?

¿Cómo descubre Maxi que su mujer le engaña?

Nadie se lo dice.

Él lo descubre por medio del cálculo, y ella le ayuda, con aquella franqueza instintiva.

Maxi es hombre a quien los celos dan una perspicacia. El amor hace de los débiles fuertes. Los celos hacen del torpe el agudo, y del criminal el polizonte (A 629/682-630/683, H 367-368).

y la impotencia, a la que se concede mucha más importancia que en BETA:

${ }^{29} \mathrm{El}$ dato de que dejó la redacción de la novela por unos meses es de Ullman y Allison; al comienzo de BETA, p. 1, se lee " 3 de Marzo 86", y la próxima fecha que consta en el manuscrito es la del final de la tercera parte de BETA, p. 677 (reverso): "6 de Dic. 86". Si el crimen de Galeote fue el 18 de abril de 1886 y la última carta que Galdós envió a La Prensa es del 9 de octubre de dicho año (publicada el 20 de noviembre) podemos suponer que estuvo cinco meses ocupado con el caso y alejado de Fortunata y Jacinta.

30 "La perspectiva de Galdós en el asesinato del obispo Martínez Izquierdo", $A G, 12$ (1977), 141-145. 
Y el pobre Maxi se esforzaba en ser marido sin poderlo conseguir $[\ldots]$

Levantóse alegre Fortunata al otro día. Maxi siguió en la cama, rendido por sus esfuerzos impotentes. Le amaba con el corazón y la mente, pero no podía pasar de aquí (A 605/658, H 253-254).

Maxi es impotente. Consulta médicos, que no pueden remediar su mal. Desde que se unió con su mujer no ha podido consumar el matrimonio. Esto le desespera y le pone en un grado de abatimiento horrible (A 825, H 463).

Las únicas dos menciones de la locura con relación al personaje no trascienden el símil:

[por los celos] Parecía un loco enjaulado, daba suspiros, se quería matar (A 649/704, H 379).

Maxi parecía un demente [cuando Juan le da la paliza] (A 667/716, H 386).

Y aun cuando el narrador dice en una ocasión (A 516, H 309-310) que Maxi padecía alucinaciones, sólo se trata de la duermevela al despertar.

Maxi tiene, como en BETA, intentos abortados de violencia: compra un revólver para matar a Fortunata pero no se atreve, quiere matarla con un cuchillo cuando descubre que está encinta pero ella se lo quita (en uno de los posibles finales que Galdós se propone a sí mismo para la novela, Maxi cose a puñaladas a Fortunata, pero estos finales hay que tomarlos como meros interrogantes que se plantea el autor).

Lo más importantes del caso es que en ALPHA el narrador casi abandona a Maxi a partir del tercer volumen, lo que no sucede ni con Fortunata, ni con Jacinta ni con Juanito. Tenemos, desde ese momento, sólo tres noticias del personaje (que en BETA habría de cobrar tal importancia, que para doña Emila Pardo Bazán Fortunata y Jacinta es la novela de Maxi Rubín): Maxi cosiendo a puñaladas a Fortunata en uno de los posibles finales (A 819, H 459), desesperado por su impotencia (A 825-826, H 463-464) y queriendo matar a su esposa con el cuchillo que ella le quita (A 831, H 466). Las últimas palabras sobre el personaje son escuetas: "Furor, desesperación de Maxi"' (A 831, H 466).

En BETA ya la cosa cambia radicalmente. La trayectoria de la locura de Maxi es extensa y minuciosa, y el personaje cierra la novela: 


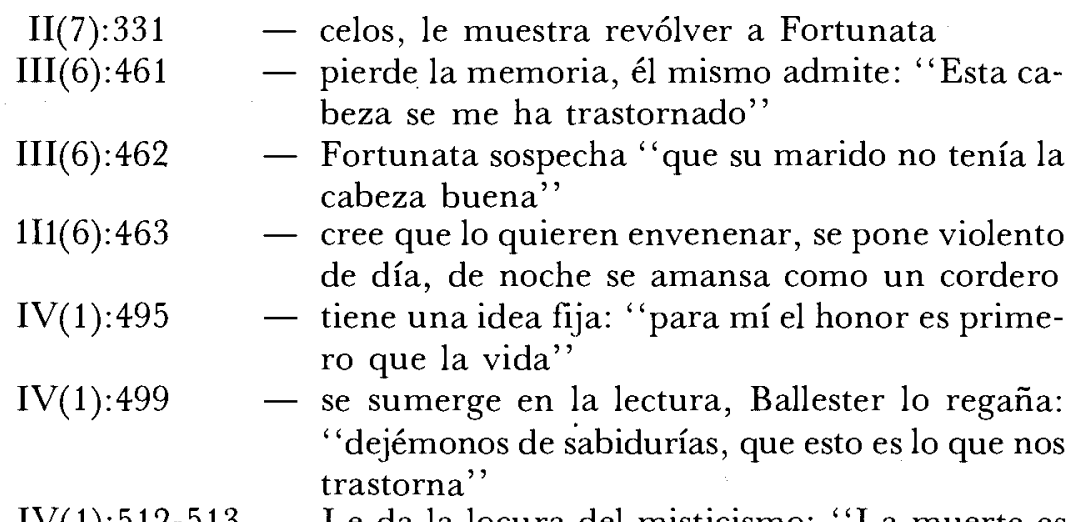

IV(1):512-513 — Le da la locura del misticismo: "La muerte es la liberación, el indulto, o sea la vida verdadera..." El narrador comenta: "más parecía un iluminado antiguo, cuya demencia se elabora en la soledad claustral, que el insensato de estos tiempos". Maxi quiere propagar esta doctrina como profeta de un Mesías que vendrá después, mientras doña Lupe dice: "Está perdido... enteramente perdido... Ya esto no tiene soldadura"

IV $(1): 519$ - compra un puñal y lo enseña a Fortunata junto con papeletas llenas de veneno para que vaya escogiendo la forma de morir: su religión ordena el suicidio

IV(3):556 - el narrador: "Maxi endilgó a su mujer algunas frases enteramente ceñidas al endiablado asunto del suicidio que constituía su demencia"

IV(3):558 - Fortunata se pregunta: “¿Será farsa todo esto de la locura?"

IV(3):559 - Fortunata sospecha que las volteretas que da Maxi [cual don Quijote en Sierra Morena] son producto de la marihuana que toma en las píldoras que le da Ballester (la "hatchisschina o extracto de cáñamo indiano")

IV(3):559 - Maxi persigue a Papitos con un cuchillo

IV(3):560 - persigue a doña Lupe con un cuchillo, "diciendo que la quería liberar'

IV(3):569 - confiesa a Ballester que "eso del Mesías, acá para entre los dos, no lo he creído yo nunca..."

IV(5):577 - a Maxi no se le permite leer nada. Le sobreviene "el furor de la lógica"

IV(5):578 - Maxi se dice: "Dios mío, me asombro de lo cuerdo que estoy",

IV(5):584 - confiesa a Ido haber estado mal, inventando religiones y queriendo que el género humano se matara 
IV(6):603 - Fortunata se pregunta, "Pero este hombre, ¿está cuerdo o está más loco que antes?' ' cuando Maxi va a verla recién parida. Él le dice: “ ¿Te acuerdas cuando yo estaba loco [...] Después me atacó lo que yo llamo la Mesianitis... Era también una modificación cerebral de los celos [...] Examínalo bien, y verás que todo era celos, celos fermentados y en putrefacción. ¡Ay, hija, qué malo es estar loco!'

IV(6):606 - Fortunata "No dudaba, no; lo denunciado por aquel hombre, que a veces parecía un demente, a veces no, revestía las apariencias de un hecho cierto",

IV(6):624 - Fortunata: "Unos dicen que estás cuerdo, y otros que estás loco. Yo creo que estás cuerdo, pero que no eres hombre",

IV(6):645 - Ballester dice que hubo que encerrar a Maxi en su cuarto después de quitarle un revólver con el que quería "fusilar a las pobres Samaniegas y a otra persona [Juan] que suele pasear por el barrio",

IV(6):651 - Maxi afirma con regocijo que su razón "vuelve a iluminarme como un faro espléndido. [...] Pero confiesa haber sido "un mártir y un loco"

IV(6):652 - Maxi: "Tía de mi alma, yo me quiero retirar del mundo, y entrar en un convento donde pueda vivir a solas con mis ideas". Luego, al llegar: "¡Si creerán estos tontos que me engañan! Esto es Leganés. Lo acepto y me callo, en prueba de la sumisión absoluta de mi voluntad a lo que el mundo quiera hacer de mi persona. No encerrarán entre murallas mi pensamiento. Resido en las estrellas. Pongan al llamado Maximiliano Rubín en un palacio o en un muladar... Lo mismo da".

Que Maxi es un caso clínico en BETA, como lo advierten Ullman y Allison, no cabe duda: una niñez infeliz con un padre violento y una madre promiscua; juventud con enfermedades psicosomáticas; contacto tenue con la realidad; impotencia a partir del matrimonio, por la culpabilidad que le produce desear a Fortunata, a la que identifica inconscientemente con su madre, en un complejo edipal compensatorio; y finalmente ruptura con la realidad, que lo lleva a intentar un asesinato religioso "típicamente esquizofrénico". Su locura es reconocida como tal por él mismo, por el narrador, y por los personajes que lo rodean: For- 
tunata, doña Lupe, Ballester. Naturalmente, la cosa no queda ahí, y Galdós le da la vuelta cervantina al asunto asimilando a Maxi a don Quijote: las lecturas lo ponen peor, se las prohiben, da volteretas como éste en Sierra Morena, y sobre todo, como Alonso Quijano, abjura de su locura al final y "muere" para el mundo al ingresar en Leganés.

¿Qué causa la locura de Maxi? Como en el caso de Anselmo (La sombra, 1870), y el de Galeote, es una idea fija: la del honor ultrajado; en los dos primeros casos, por la mujer "adúltera", en el tercero, por la autoridad "arbitraria". Claro que la idea fija del honor y los celos estaba ya en ALPHA, pero no como enfermedad, sino como mala literatura. Galdós probablemente intuyó el peligro de prohijar un personaje ridículo, de los de capa y espada, y decidió darle otra dimensión más profunda, un tratamiento psicológico. De ahí que su idea fija esté acompañada en BETA de pérdida de memoria, alteraciones violentas de humor, delirio de persecusión, intentos de homicidio y diversas manías: la lectura, el misticismo, la lógica, el ascetismo. De celoso vulgar en ALPHA, pasará a hombre atormentado por la experiencia de la niñez que ve repetida en su edad adulta, y cuyo deterioro psicológico se traza paso a paso hasta su final en el manicomio. Hay que señalar que la idea fija es una noción de la psiquiatría temprana que Galdós conocía por sus lecturas. En Torquemada en el purgatorio (1894) menciona la Neurypnología de James Braid, y el nombre de Ambroise-Auguste Liébault. Braid fundó la hipnosis médica y formuló la doctrina del monoideísmo en 1842 y 1850 ; a partir de 1866 , en $D u$ sommeil, Liébault convertiría ésta en la de la "idea fija'"31.

Cabría pensar, entonces, que Galdós se sensibilizó (no por primera vez, sin duda: pensemos en La sombra) al problema de la locura con el caso de Galeote, cuya experiencia pasó por el tamiz de sus lecturas psiquiátricas, y que esto lo preparó para enfrentarse otra vez al casi descartado Maxi de ALPHA para darnos un "loco-cuerdo"' acabado en BETA ${ }^{32}$.

Mercedes López-BaralT

Universidad de Puerto Rico, Río Piedras

31 Bosch, op. cit..

32 La otra loca de la novela es Mauricia, cuyo desarrollo sigo en "Fortunata y Jacinta en gestación: de la versión ALPHA a la versión BETA del manuscrito galdosiano". 